\title{
Assessing Learning Motivation of Library- Information Majors at Can Tho University, Vietnam
}

\author{
Linh Ngoc Le ${ }^{1}$, Anh Thu Bui ${ }^{2}$ \\ ${ }^{* 1}$ Lecturer,${ }^{* 2}$ Student, School of Social Sciences and Humanities, \\ Can Tho University, Vietnam
}

\begin{abstract}
Students' motivation as a performance aspect of modern librarianship tertiary programs in Vietnam has not yet been discussed in library and information science literature. With its three-fold theoretical rationale (that motivation and academic achievement are related, motivation changes through time, and motivation is regulated by numerous factors) formulated from Ryan and Deci's Self-Determination Theory (1985), the study seeks to quantatively measure students' motivation using a 6-item questionnaire delivered to 164 Library and Information majors (LIMs) at Can Tho University (CTU). Cronbach's Alpha was calculated to check the questionnaire's internal reliability, while frequencies and Pearson correlation coefficients revealed a non-relationship between LIMs' motivation level and their grade point average, a reducing number of highly-motivated LIMs, and causal sources of low motivation. These three findings necessitate motivation-raising solutions, one being making motivation a strong predictor of academic achievement (which advocates the 1989's view of Pintrich on motivation research and that of Deci and Ryan's 1985); and another: building motivation by satisfying students' needs for competence, relatedness, and autonomy (which encompasses the main postulate of Deci and Ryan's 1985-conceived Self-Determination Theory). The findings and the solutions can bea source of reference for other higher educational institutions that offer library-information programs.
\end{abstract}

Keywords --Vietnam, Can Tho University, assessing learning motivation level, library and information students, library and information undergraduate program, curriculum improvement, motivation-impacting factors

\section{INTRODUCTION}

The study propagates the importance of being aware that learners' motivation is central to learning and teaching, and that it is subject to change positively or negatively under the influence of numerous factors, a lot of which educators can harness to ensure their curriculum is operated on a student-centered basis.

Education reform advocates have dedicated huge amounts of time and energy to improving public schools and raising student achievement. But with attention currently focused on factors like improving teacher quality, overhauling curriculum and standards, and developing new assessments, one major factor is being overshadowed: the motivation of the students themselves. Even with the best administrators, faculty, curriculum, and materials in place, if students are not motivated to learn and excel, achievement gains will be difficult, if not impossible [44].

To better upgrade its curriculum fornational and regional accreditation as required by the quality assurance culture pursued by CTU, one of the must-have preparations the Library and Information Management Department should do is to conduct a "motivation check" amongst its students. The evidence gathered can inform the treatment of motivation according to its role and impact on learning and teaching in the Department's all-time mission of curriculum renovation. This resulting motivation-oriented program is, in the time to come, expected to prove empowering in the knowledge economyand competitive in the market-driven education. 


\section{METHODOLOGY AND LITERATURE REVIEW}

Studies on learners' motivation revolve around these three aspects: how motivation level relates to academic achievement level, how it changes, and what impacts it.

Students' learning motivation is found to lead them to true learning [27], decide their success or failure in a course [41], direct the use of learning strategies [15], and correlate, from relatively to highly, with their course grades [28],[4], [31], [1],[16], [51], [20],[37]. However, there are also some studies which don't find such relationship between academic resilience and cumulative grade point average among college students, reporting no signifiant correlations [23], or revealing only a small positive correlation $(\mathrm{r}=0.15)$ [21].

Motivation shifts in forms when people get older [46] or move through different contexts such as geographical relocations, illnesses, and war [5]. Employees' motivation to work increases in good working environment [24], and the amount of change in theirs increases over time as there are more formal and informal organizational influences[32]. Students' motivation changes according to classroom norms and interpersonal events that their teachers set up [43], and to their own personal belief systems [19], and should no longer be "seen as the stable individual difference factor as it was once believed to be" [47].

Students' motivation can be increased or decreased based on many different factors, especially ones from their teachers such as immediacy [45], instructional techniques and grading strategies [6],[25], [13]. If an individual engages in an activity out of interest and then is subsequently given a reward such as money [7] or in the form of points [29], then the intrinsic motivation he/she used to have for that activity will be declined. Deci et al. [9] confirmed that expected and tangible extrinsic rewards can undermine intrinsic motivation for an activity by shifting the individual's reasons for performing the task from internal (e.g., interest, fun) to external (e.g., to receive the reward). However, when freed from the pressures of grades and instead focused on being learners, even for students who are highly motivated by grades and test scores now have their engagement, enthusiasm, motivation, and determination drastically increased [41], [27]. Other sources of motivation include parental warmth, autonomy granting, and supervision [14]; and student-to-student relations, student-faculty interaction as well as critical thinking skills [39]. [52] proposes that improving student motivation in the classroom is a function of five key components: students' individual needs, teachers' knowledge and skills, experience-relevant contents, experimental methods, and social/parental supportive environment.

This study benefits from the studies reviewed above and tests their findings on CTU's LIMs, guided by objectives and research questions as follows:

Objective 1: Explore the relationship between LIM's motivation and their academic achievement

Objective 2: Examine the changing motivation levelsamong LIMs

Objective 3: Investigate the factors that impact LIMs' motivation

Objective 4: Propose possible solutions for the Library-Information faculty to enhance LIMs' motivation

Research question 1: How does LIMs' motivation relate to their academic achievement (as indicated in their Current Cumulative Grade Point Average)?

Research question 2: What are the patterns of motivation level change among LIMs?

Research question 3: What factors affect LIMs' motivation?

Research question 4: In what ways could LIMs' motivation be enhanced?

$\mathrm{H}_{01}$ : LIMs' Cumulative Grade Point Average does not relate to their motivation level.

$\mathrm{H}_{02}$ : LIMs' motivation does not decline with LIMs' seniority.

$\mathrm{H}_{1}$ : Teacher-related factors have a great impact on LIMs' motivation level.

$\mathrm{H}_{2}$ : Students't first drives in choosing Library-Information program can shape how their motivation grow during the learning process.

These findings are expected to provide the Library-Information Department with scientific evidence to make informed decisions regarding motivational aspects in improving its curriculum. They will also filla gap in 
learners' motivation research literature with an understanding about student motivation change and motivationchanging factors in library-information instruction.

The central concept of this study, motivation, as well as its theoretical framework, is adopted from Deci and Ryan's Self-Determination Theory (SDT).

Motivation is the intrinsic and/or extrinsic drive to do something. Intrinsic motivation is characterized by doing something purely because of enjoyment or fun. In contrast, with extrinsic motivation, a person tends to do a task or activity mainly because doing so will yield some kind of reward or benefit upon completion. [8]

The core idea of Deci and Ryan's SDT is that motivation, performance, and development will be maximized within social-contextual conditions/factors that provide people the opportunity to satisfy their basic innate psychological needs for competence, relatedness, and autonomy (or self-determination). The satisfaction of the three basic psychological needs nurtures intrinsic motivation and promotes internalization of values and regulatory processes, leading to the desired educational outcomes such as interest in learning, a valuing of education, and learners' confidence in their own capacities and attributes.

A large body of educational research that were reviewed in [10] supports the SDT perspective. They reported significant positive correlations between self-determined motivation and various educational outcomes (such as positive academic performance, greater conceptual learning, more positive emotions, more enjoyment of academic work, course grades, etc.) across the age span, from early elementary school to college students. They also identified the degrees to which intrinsic motivation was enhanced or diminished by various social conditions that supported or thwarted students' three basic psychological needs for competence (e.g., optimal challenges and constructive feedback), relatedness (e.g., parental involvement and peer interaction), and autonomy (e.g., choices of tasks and non-controlling ambience).

\section{METHODS}

This study was conducted by quantitative approach, analyzing data collected from a questionnaire to confirm whether there is a relationship between LIMs' motivation level and their cumulative GPA, whether their motivation decreases with their seniority, and what factors regulate their motivation changes. These findings inform the possible suggestions proposed to enhance LIMs' motivation.

LIMs' from all four years were chosen to provide sufficient data that could portrait how their self-reported motivational levels fluctuate among the four groups. Using random sampling and Krejcie and Morgan's Sample Size Table [26], a sample of 164 LIMs was drawn from a 283-LIM population, with confidence level being $95 \%$ and confidence interval $5 \%$. Each of four years' groups accounted for $25 \%$ of the 164-LIM sample.

The questionnaire comprises of 6 questions eliciting information about:

1. Current Cumulative Grade Point Average

2. Self-evaluated current motivation level (reported on a seven-point Likert scale anchored by: No motivation $=0$ to Very high motivation $=6$ )

3. Factors that yield the reported High motivation (levels 4-6)

4. Sources that cause the reported No-to-Low motivation (levels 0-2)

5. Reasons for majoring in Library-Information field of study

6. Suggestions for teachers of the Library-Information Department to enhance LIMs' motivation

Before the questionnaire was piloted to spot and fix all possible weaknesses in wording, the motivation scale as a self-report single item Likert scale had been conceived based on extensive theoretical considerations[2], [3], [11], [17], [33], [34], [38], [48], [49], [50], [53], [54]. In addition, the scale was tested and retested with those 80 LIMs(20 from each group) whose Test 2 's responses showed a 0.87 correlation with Test 1 's(between-test interval being 20 days). 
DOI: $10.51386 / 25815946 / \mathrm{ijsms}-v 4 \mathrm{i} 6 \mathrm{p} 115$

Volume: 4 Issue: 6

November to December 2021

https://www.ijsmsjournal.org

Of the 164 official questionnaires that were handed in, 162 were properly filled and so used. This number still guaranteed the sample size required for a 283-student population. Having been inputted into SPSS Statistics V23, the data first showed a Cronbach's Alpha coefficient of 0.936, which indicated that the questionnaire had acceptable internal consistency and therefore the data were reliable enough to be used.

\section{FINDINGS}

1) How does LIMs' motivation relate to their academic achievement (as defined by Current Cumulative Grade Point Average or GPA)?

Tables 1 and 2 show cumulative GPAs and motivation levels, as self-reported by LIMs through the survey:

Table 1: LIMs' self-reported current cumulative GPAs

\begin{tabular}{ccccc}
\hline $\begin{array}{c}\text { Cumulative } \\
\text { GPA }\end{array}$ & $\begin{array}{c}\text { Acceptable } \\
\text { performance } \\
2.0-2.49\end{array}$ & $\begin{array}{c}\text { Creditable } \\
\text { performance } \\
2.5-3.19\end{array}$ & $\begin{array}{c}\text { Superior } \\
\text { performance } \\
3.2-3.59\end{array}$ & $\begin{array}{c}\text { Outstanding } \\
\text { performance } \\
3.6-4\end{array}$ \\
\hline Percentage & $1 \%$ & $55.9 \%$ & $41.2 \%$ & $2 \%$ \\
\hline Number & 2 & 90 & 67 & 3 \\
\hline
\end{tabular}

Table 2: LIMs' self-reported present motivation levels

\begin{tabular}{|c|c|c|c|c|c|c|c|}
\hline $\begin{array}{c}\text { Motivation } \\
\text { level }\end{array}$ & $\begin{array}{c}\text { No } \\
\text { motivation } \\
0 \\
\end{array}$ & $\begin{array}{c}\text { Very low } \\
\text { motivation } \\
1 \\
\end{array}$ & $\begin{array}{c}\text { Low } \\
\text { motivation } \\
2 \\
\end{array}$ & $\begin{array}{c}\text { Medium } \\
3\end{array}$ & $\begin{array}{c}\text { Pretty high } \\
\text { motivation } \\
4\end{array}$ & $\begin{array}{c}\text { High } \\
\text { motivation } \\
5 \\
\end{array}$ & $\begin{array}{c}\text { Very high } \\
\text { motivation } \\
6 \\
\end{array}$ \\
\hline Percentage & $0.0 \%$ & $1.2 \%$ & $11.7 \%$ & $28.4 \%$ & $29.0 \%$ & $24.7 \%$ & $4.9 \%$ \\
\hline Number & 0 & 2 & 19 & 46 & 47 & 40 & 8 \\
\hline
\end{tabular}

A Pearson correlation analysis was conducted to examine whether there is a relationship between LIMs' motivation level and their Cumulative Grade Point Average. The results revealed no significant relationship between them $(\mathrm{r}=0, \mathrm{~N}=162, \mathrm{p}=0.549)$. While there is widespread literature consensus on how motivation augments academic achievement, this finding almost agrees with [23] and [21], which reported "no significant correlations" or "only a small positive correlation" between motivation and GPAs among college students. In other words, the hypothesis that LIMs' Cumulative Grade Point Average does not relate to their motivation level $\left(\mathrm{H}_{01}\right)$ can be accepted.

This insignificant relationship between motivation and GPA can be understood in part because grades are just one of the many factors that reflect academic achievement [42]. A student may have motivation affect other aspects of his/her academic achievement such as operational knowledge, real-life experience, extra-curriculum activities, social contacts, etc., rather than their GPA. As Lamb-Sinclair [27] experienced from her class, there are students not motivated by grades. They can fail a class but they learn valuable life lessons and gain a sense of authentic self-identity, or autonomy (also a kind of educational outcome that progressive educators all wish students to demonstrate) that guides them through college, as well as challenges in real life: "I never push myself to do things I don't believe in".

A similar case is observed by [6], when approaches to teaching and learning take into account all the cognitive and emotional factors exhibited in the students, even an inherently-unmotivated student can participate effectively, get good marks, and is accordingly considered highly motivated. In contrast, a highly motivated student can be mistaken (by teachers) as an unmotivated one if the lessons or activities are by themselves not intellectually and emotionally engaging to him/her. This is a matter of motivation changing, and so does academic performance, in varying classroom cultures, which was also addressed in [43].

Cases of students who report low motivation but high performance and vice versa can also be explained by Paul Pintrich's model - Motivated Strategies for Learning Questionnaire (MSQL) - an interplay between motivation and cognition [35]. To improve teaching and learning, we should understand student performance. A reliable way to 
understand it is to learn about the motivation-cognition dynamics in each student. The MSLQ instrument helps us gain that knowledge by having students self-report on 6 motivation subscales and 9 learning strategies scales [12]. Applying Paul Pintrich's approach to the case at hand, high-motivated students could be low-achieving because they don't have effective learning strategies or they are not aware that learning strategies can be learned and brought under their control by letting these be motivated by the high-motivation they already have. In other words, they don't know that they can self-regulate their learning by getting their motivation to interface and interact with their cognition. Likewise, students who consider them as low-motivated may not even understand why they can be highachieving. As "laypeople" to psychology, their knowledge about motivation might not be sufficient for them to realize what they assessed as "low" was their intrinsic motivation and they can achieve high GPA thanks to their extrinsic motivation or any of the four types of it: external, introjected, identified, and integrated regulations. Even though Lamb-Sinclair might argue "graduating from high school and college with higher grades actually represents something more profound in the students: intrinsic motivation and persistence" [27], the "intrinsic motivation" she assumes could be the latter type of extrinsic motivation: integrated regulation. Being the closest to intrinsic motivation, integrated regulation is actually consistent with an individual's other values and needs and becomes part of one's self-identity [18].

\section{2) What are the patterns of motivation level change among LIMs?}

Another Pearson correlation analysis was conducted to examine whether there is a relationship between LIMs' motivation levels and the years that they are in. The results revealed a significant and negative relationship between these two variables $(\mathrm{r}=-0.45, \mathrm{~N}=162, \mathrm{p}=0.00)$. The correlation was medium in strength, according to [40]. In light of this, the hypothesis that LIMs' motivation does not decline with their seniority $\left(\mathrm{H}_{02}\right)$ can be rejected. The lower levels of LIMs' motivation were associated with the more senior years that they are in (see Table 4).

Table 3: Correlation between Year and Motivation level

\begin{tabular}{|c|c|c|c|}
\hline \multicolumn{4}{|c|}{ Correlations } \\
\hline & & Year & Motivation level \\
\hline \multirow{3}{*}{ Year } & Pearson Correlation & 1 & $-.449^{* *}$ \\
\hline & Sig. (2-tailed) & & .000 \\
\hline & $\mathrm{N}$ & 162 & 162 \\
\hline \multirow{3}{*}{$\begin{array}{l}\text { Motivation } \\
\text { level }\end{array}$} & Pearson Correlation & $-.449^{* *}$ & 1 \\
\hline & Sig. (2-tailed) & .000 & \\
\hline & $\mathrm{N}$ & 162 & 162 \\
\hline
\end{tabular}

**. Correlation is significant at the 0.01 level (2-tailed).

This declining motivation among LIMs can also be seen through the distribution of high and low motivation levels among the four groups:

Table 4: Distribution of low and high motivation levels across the four LIMs groups

\begin{tabular}{cccc}
\hline Motivation level & $\begin{array}{c}\text { very low }- \text { low } \\
\text { motivation } \\
1-2\end{array}$ & $\begin{array}{c}\text { medium } \\
\text { motivation }\end{array}$ & $\begin{array}{c}\text { pretty - very high } \\
\text { motivation } \\
4-6\end{array}$ \\
\hline Percentage & $13 \%$ & 3 & $58.6 \%$ \\
Number $(\mathbf{1 6 2})$ & 21 & $28.4 \%$ & 95 \\
\hline Freshmen $(\mathbf{n = 4 1 )}$ & 2 & 46 & 34 \\
Sophomores $(\mathbf{n}=\mathbf{4 0})$ & 3 & 5 & 29 \\
Juniors $(\mathbf{n}=\mathbf{4 0})$ & 7 & 8 & 20 \\
Seniors $(\mathbf{n}=\mathbf{4 1})$ & 9 & 20 & 12 \\
\hline
\end{tabular}


Data in Table 4 show that the number of LIMs having high motivation shrinks as they "move" from the first to the fourth year (from 34 to 12 LIMs) and junior-senior LIMs overwhelmingly make up over $3 / 4$ of the lowmotivated group $(n=16 / 21)$. This further illustrates the significant and negative relationship between motivation level and years' seniority already found above.

Motivation fluctuating over time (or in different living/working/study environments) is solidly observed in all the studies reviewed in the literature. As for the speed of change, which is slower among freshmen and sophomores (from 2 to 3 low-motivated LIMs, 5-8 medium-motivated, 34-29 highly-motivated) than among juniors and seniors (7-9, 13-20, 20-12), it is similar to Oberfield's finding: modest change in motives among an entering group of police officers during the first two years of their employment but an increasing amount of change over time under more formal and informal organizational influences [32].

\section{3) What factors affect LIMs' motivation?}

Following are the factors that were reported by $58.6 \%$ of highly-motivated LIMs $(n=95)$ to have helped nurture their pretty-high to very-high motivation (levels 4-6):

\section{Table 5: Factors that yield the reported High motivation (levels 4-6)}

\begin{tabular}{llcc}
\hline & \multicolumn{1}{c}{ Factors that build high motivation } & n/95 & \% \\
\hline 1 & Instructors' technical, scientific and methodological expertise & 52 & 54.7 \\
2 & Good fit between the program and my ability, qualities and values & 46 & 48.4 \\
3 & Optimism about the future of the library-information career & 40 & 42.1 \\
4 & Family support & 39 & 41.1 \\
5 & CTU's sufficient provision of learning facilities for this program & 29 & 30.5 \\
6 & Effective learning methods & 24 & 25.3 \\
7 & Interest in the field of library-information & 20 & 21.1 \\
8 & Peer support from classmates & 14 & 14.7 \\
\hline
\end{tabular}

The impacting factors illustrated in Table 5 all center around the teacher (factor 1), student (factors 2, 3, 6, 7), content (factors 1,2), method (factor 1), and environment (factors 4, 5, 8) - the five key components that Williams and Williams propose to be used as bases for developing motivation-building strategies in the classroom [52].

"Instructors' expertise" being the top motivation-building factor is very encouraging to the faculty members of the Library-Information Department, who have consistently made great efforts in professional and scientific expertise development since its establishment almost 15 years ago. Up to this point, the hypothesis that teacherrelated factors have a great impact on LIMs' motivation level $\left(\mathrm{H}_{1}\right)$ proves valid.

The second- and third-placed factors in the list: "A good fit ..." and "Optimism ..." can be seen as justifying CTU's consistent efforts in organizing the Orientation Day annually on its campus for high school students (before their high school leaving exam). On this day, through the introduction and consultation each program's counselling team, high school students can better determine whether the programs they have wished to study, together with their careers prospects, fit their ability, quality, and expectations. Students who have clear intention in choosing their study programs stands to benefit greatly from this event.

While there was no case of zero level of motivation (no motivation), 13\% students ( $\mathrm{n}=21 / 162)$ who found themselves having very low to low motivation levels reported the following sources of low motivation: 
Table 6: Sources that cause the reported Very low-to-Low motivation (levels 1-2)

\begin{tabular}{lcc}
\hline \multicolumn{1}{c}{ Sources of low learning motivation } & $\mathbf{n} / \mathbf{2 1}$ & $\mathbf{\%}$ \\
\hline Pessimism about the future of the library-information career & 11 & 52.4 \\
Lack of interest, suitable ability or qualities for this field of study & 9 & 42.9 \\
Financial difficulties & 6 & 9.5 \\
Others (Uninspiring instructors; Limited practice-based contents; & 3 & 14.4 \\
Shortage of learning resources) & & \\
\hline
\end{tabular}

Among 235 universities in Vietnam (as of 2018), there are only 7 universities that offer Bachelor's degree programs in Library-Information management or science (3 in Hanoi, 3 in Ho Chi Minh City, and 1 in the Mekong Delta). The seemingly humble labor market for library-information career can explain why "Pessimism about the future of the library-information career" is the top source of low motivation among students. Moreover, since the required entrance score for this program at CTU is set quite low (12, as compared to 25 as the highest required score for some other programs), together with the CTU's policy on offering opportunities to students with their cumulative GPA above 2.0 to pursue dual degree, every year about half of the students admitted into this program are those rejected from other programs that have higher required entrance scores. Table 7 shows students' reasons why they chose to enroll in Library-Information program, among which we can see extrinsic motives such as "To earn a dual degree with the $2^{\text {nd }}$ field of study being my truly favorite", "To earn a bachelor degree in any field as wished by parents", or "I have low entrance exam scores". Seeing these reasons for choosing a program, it is understandable why there are still many students claiming they don't have "suitable abilities or qualities for this field of study".

Table 7: LIMs' reasons for enrolling in CTU's Library-Information program

\begin{tabular}{lcc}
\hline \multicolumn{1}{c}{ Reasons } & n/162 & \% \\
\hline To gain expertise for my career in Library-Information management & 82 & 50.6 \\
To experience the civilizing and rewarding life of a university student & 60 & 37.0 \\
To earn a dual degree with the $2^{\text {nd }}$ field of study being my truly favorite & 33 & 20.4 \\
To live up to my parents' expectations (a bachelor degree in this field or any) & 13 & 8.0 \\
Others: (I like this field; I have low entrance exam scores; It fits my abilities; It can & 7 & 4.2 \\
guarantee high-paying jobs) & & \\
\hline
\end{tabular}

In view of the sources of low motivation existing in $13 \%$ of LIMs $(n=21 / 162)$ and the extrinsic reasons why almost $50 \%(\mathrm{n}=162)$ students chose the Library-Information program in the beginning, the hypothesis that students' first drives in choosing Library-Information program can shape how their motivation grow during the learning process $\left(\mathrm{H}_{2}\right)$ can be confirmed.

The pro- and anti-motivation factors examined so far have contributed to the third finding of this study that LIMs' motivation level can be enhanced or diminished by a number of social-contextual factors.

Back to Table 7, the top two reasons in it, which purely represent intrinsic motivation, are consistent with the finding by [22] that "gaining specialized knowledge" and "developing social contacts" are the top factors that constitute learning motivation of their students. Maslow's famous Hierarchy of Needs [30] can also help enlighten why the top two intrinsic motives line themselves up in this order but not the other way round: students need a career to earn their living (a basic need) before they can attend to needs higher up the hierarchy such as "civilizing and rewarding life" (a self-fulfillment need). 


\section{4) In what ways could LIMs' motivation be enhanced?}

Solution 1: Making motivation a strong predictor of GPA (because GPA is important in academic achievement assessment and vital in its turn as a source of extrinsic motivation)

The fact that LIMs' motivation level does not related to their Cumulative GPA, which means there are students who have high motivation but low GPA and those who have low motivation but high GPA, has some implications for educators. Since GPA is an important one of the many indicators of academic achievement and is, for its convenience, universally used in competence assessment or recruitment, educators should help make motivation a strong predictor of GPA.

First, for highly-motivated students who are low-achieving, there should be further research aimed at discovering all the dynamics in their motivation to see which has not yet been fully extended in order to help them achieve as high as their motivation can allow. According to [35] and [36], learning motivation is made up of not only beliefs or values towards the learning task, but also the learning strategies that are motivated by such beliefs and values to help learners successfully conquer the learning task. As remarked by [19], students' personal belief systems can set them on distinct motivational routes, either positive or negative. Students who believe intelligence is fixed rather than malleable and so seek to protect perceptions of their competence by avoiding challenges experience losses of intrinsic motivation over the course of an academic year. Therefore, if there are students who are found to be highly-motivated but are observed as not to have good learning strategies, as educators, we should have timely intervention to help them develop these strategies then help keep theirs rightly and constantly motivated before they can lose motivation ruefully as a result of their not having been able to highly attain the "visible" outcomes that most parents and employers like to see such as GPAs.

Second, for low-motivated but high-achieving students, there should also be additional research to realize all possible motivational dimensions in a learner as well as the role each embraces in order to look for ways of assembling these dimensions into one powerful dynamism, making learners highly-motivated and sustaining their high achievements. To most laypersons, what they usually think of as motivation is just one dimension of it: intrinsic motivation. Accordingly when they find themselves "low-motivated in learning in general but still having high GPA", an educational psychologist, based on relevant theories of motivation, such as the Theory of SelfDetermination, would phrase this more exactly as "low intrinsically motivated in learning but high extrinsically motivated for grades". Whenever grades are still important in academic achievement assessment, anything that helps achieve them, such as extrinsic motivation, should be made aware of among learners so that they can better nurture it. Teachers can also help shape how extrinsic motivation grows inside students, thereby harnessing the power of it. But how? According to the Theory of Self-Determination, the four types of extrinsic motivation (external, introjected, identified, and integrated regulations) mean there are four differing motivation degrees that a requested behavior can be internalized: amotivation, unwillingness, passive compliance, active personal commitment. When teachers wish to foster in students an extrinsically motivated behavior of, for example, studying hard, this regulation can be integrated into their sense of self at four degrees: they don't obey, they obey unwillingly, they comply passively, or they actively fulfill it. The active personal commitment comes into play when such regulation is fully assimilated to the self, which means it has been evaluated and brought into congruence with the students' values and needs. Hence the key here is teachers being able to understand students' values and needs. Although it is still considered extrinsic (responsive to outer outcomes rather than to inner enjoyment), integrated motivation shares many qualities with intrinsic motivation. Knowing this, teachers should request learning behaviors that can be internalized by students in the forms of identified or integrated regulations (personally important to them and contiguous with their values), rather than external or introjected regulators (reward or obligation). When completely integrated into the learners' belief system, this type of extrinsic motivation can become as sustainable as intrinsic motivation. If not grown in a methodical way, extrinsic motivation can die away before students can attain their next achievement. As can be seen in reality, rewards or obligations cannot always keep a person motivated.

Solution 2:Building motivation by satisfying the students' basic innate psychological needs for competence, relatedness, and autonomy 
Given the top three factors making highly-motivated LIMs drop in numbers all the way down to their senior year that are discussed in Finding 3, the Library-Information Department can consider working towards some solutions suggested by the students (see Table 8).

Table 8: Motivating solutions proposed by students

\begin{tabular}{lcc}
\hline \multicolumn{1}{c}{$\begin{array}{c}\text { (What suggestions would you give teachers of the Library-Information } \\
\text { Department to enhance LIMs' motivation?) }\end{array}$} & n/34* & \% \\
\hline Provide regular career orientation or job shadowing programs & 13 & 37.5 \\
Offer hand-on training on practical skills tailored to future careers & 12 & 34.7 \\
Hold ongoing advisory workshops on learning strategies and methods & 10 & 28.4 \\
Make learning tasks less demanding for better comfort in learning & 6 & 18.8 \\
Network LIMs of all generations across the country & 5 & 15.3 \\
\hline
\end{tabular}

* Among 162 properly-responded questionnaires, there were 34 with Question number six completed with suggestions for the Library-Information Department to enhance LIMs' motivation.

To help those LIMs feel more optimistic about the future of the library-information career, the Department should "provide regular career orientation or job shadowing programs", "offer hand-on training on practical skills tailored to future careers", and "network LIMs of all generations across the country". These ways, when combined, can help LIMs better experience real-life working environments in the field of library-information, be confident about their being ready in the skill sets required for their careers, and feel assured about the not-so-humble libraryinformation career market when seeing how vast the network of LIMs is and how many chances there are for them to learn and develop their career.

To settle the "lack of interest, suitable ability or qualities for this field of study" matter, the Department can consider not admitting into the programs students rejected from other programs if teaching only students who are really serious about having a career in library-information is very important to its faculty members. If it can tolerate teaching those students who didn't mean to pursue the library-information field from the very beginning, then the Department should have special treatment in teaching and managing this group so that they can feel better suited to the library-information world. Supplement solutions included in the special treatment can also be "hold ongoing advisory workshops on learning strategies and methods" (since they happened to resort to this program, it may be difficult for them to readily come up with strategies for the learning process) and "make learning tasks less demanding for better comfort in learning" (they are not intrinsically motivated for this field, so any ordinary task can become too demanding for them).

As for "financial difficulties", CTU is always there to help students facing this issue. With CTU being very responsive to solving this, the Department can exercise more care to encourage students to be willing to report their financial difficulties as early as possible so that the CTU's Student Affairs Office can offer timely assistance, saving them from becoming too pre-occupiedby financial matters to focus on learning.

According to the core idea of Self-Determination Theory [8], when these three challenges can be successfully met, students will become proactive and engaged in the learning from which they develop and in the career in which they will be functioning because they can now feel competent (understand how to attain various outcomes in learning and career with suitable learning strategies, career-oriented skills, and real-life experience), related (develop secure and satisfying connections with other LIMs to know they are not alone pursuing unrealistic things), and autonomous (be free from financial constraints to lead their learning journey in the most fulfilling way). In other words, students' motivation, performance, and development will be maximized if we create socialcontextual conditions that provide them with the opportunity to satisfy their basic innate psychological needs for competence, relatedness, and autonomy. 
About the least-chosen sources of low motivation (Uninspiring instructors; Limited practice-based contents; Shortage of learning resources), although they don't represent a substantial number of students, the Department should also address these issues. Since these concerns sound related to certain course, rather than the entire learning experience in the program, there should be surveys or interviews at the course level to see whether these claims still come up. If they do arise, they should be checked against the credibility of the claim holders shown through their performance in class. That means such claims as "Uninspiring instructors", "Limited practice-based contents", "Shortage of learning resources" can be considered reliable when they are voiced by a statistically significant number of students who don't skip class and who are serious about their learning. Apart from the issue of instructors being inspiring or not, which is very subjective and situational in nature, the CTU's Library-Information program was planned to have a reasonable proportion of theoretical and practical contents, as well as to run on a sufficient provision of learning materials prescribed by the experts who conceived this program and the faculty members who have actually executed it. Students should be well aware that there are courses which are essentially theoretical in orientation, and whether or not they have enough learning resources depends on their independent and voluntary search for required and additional courses' readings. Not every reading will ever be photocopied and brought to class and placed into their hands with an explicit warning that they will be punished if they don't read before their lessons or use these materials for their assignment.

\section{CONCLUSION AND RECOMMENDATIONS}

This study has been conducted to find evidence about the present motivation level of Library-Information students of Can Tho University to serve as a reference for motivation-related decisions to be made in the upcoming curriculum renovation of the Library-Information program. Based on the Theory of Self-Determination developed by Ryan and Deci [8] as its theoretical framework, as well as other previous related studies as contextual foundation, the study comes up with three important findings. First, the motivation level of Library-Information students does not relate to their cumulative grade point average. In other words, high motivation level cannot predict high cumulative grade point average. Second, the number of highly-motivated Library-Information students drops when they "reach" the final year due to causes such as "Pessimism about the future of the library-information career", "Lack of interest, suitable ability or qualities for this field of study", and "Financial difficulties", which make up a part of the third finding of this study. Significant motivation-building solutions suggested by Library-Information students who took part in the survey include "Provide regular career orientation or job shadowing programs", "Offer hand-on training on practical skills tailored to future careers", or "Network LIMs of all generations across the country", etc. These solutions were evaluated and recommended to be adopted to make students feel better competent, related, and autonomous in learning, thereby building up their motivation as envisioned by the Theory of Self-Determination. Implications of this study can be put as follows. Motivation impacts learning and teaching, so we should be mindful of its existence. Motivation changes, so we should care about its present magnitude or intensity. Motivational changes are regulated by different forces, so we should harness these forces to maintain high motivation level while enhancing the low one. Since it is what makes learners choose a study program, helps them learn effectively during the process, and encourages them to follow through the end, learners' motivation should be considered fundamental to how educators shape and grow an educational program.

Motivation is a central part of a student's educational experience from preschool onward, but it has received scant attention amid an education reform agenda focused mainly on accountability, standards and tests, teacher quality, and school management [44].

As educators, we need to make a habit of periodically collecting evidence about students' motivation to integrate these facts into the decisions to be made in the recurring task of curriculum improvement. Then every innovation introduced from this periodic improvement evidenced by facts about students' motivation can be more feasible because it is tailored to students' motivational orientations. As researchers, we need to develop an approach that can allow more objective and reliable measurement of learners' motivation to better support studies aimed at assessing motivation to improve teaching and learning. As teachers, we should be mindful about how motivation impacts teaching and learning, dedicated to fostering and enhancing motivation in students. As students, they should choose a university program based on their true competence and interest, plus the consultation from the program's 
counselling team. This can save students from wasting their time and money on a program for which they are not intrinsically-motivated. It can also save teachers from trying in vain to help uninterested students realize their full potential. As we know well from the Theory of Self-Determination, extrinsic motivation cannot last long if the requested learning behavior does not fit the learners' interests. Those who don't know this could view teachers as pedagogically incompetent, which can even lead teachers into doubting their own capabilities.

\section{REFERENCES}

[1] Alva, S.A. (1991). Academic invulnerability among Mexican American students: The importance of protective resources and appraisals. Hispanic Journal of Behavioral Sciences, 13(1), 18-34.

[2] Bergkvist, L. (2014). Appropriate use of single-item measures is here to stay. Mark Lett, 26(3), 245-255. 10.1007/s11002-014-9325-y

[3] Bergkvist, L., \& Rossiter, J. R. (2007). The predictive validity of multiple item versus single-item technology of the same constructs. Journal of Marketing Research, 44, 175-184.

[4] Broussard, S.C., \& Garrison, M.E.B. (2004). The relationship between classroom motivation and academic achievement in elementary school-aged children. Family and Consumer Sciences Research Journal, 33(2), 106-120.

[5] Carstensen, L.L. (2006). The influence of a sense of time on human development. Science, 312(5782), 1913-1915.

[6] Danili, E., \& Reid, N. (2004). Some strategies to improve performance in school chemistry, based on two cognitive factors. Research in Science \& Technological Education, 22(2), 203 - 226.

[7] Deci, E.L. (1971). Effects of externally mediated rewards on intrinsic motivation. Journal of Personality and Social Psychology, 18, $105-115$.

[8] Deci, E.L., \& Ryan, R.M. (1985). Intrinsic motivation and self-determination in human behavior. Plenum Press, New York.

[9] Deci, E.L., Koestner, R., \& Ryan, R.M. (1999). A metaanalytic review of experiments examining the effects of extrinsic rewards on intrinsic motivation. Psychological Bulletin, 125(6), 627.

[10] Deci, E.L., Vallerand, R.J., Pelletier, L., \& Ryan, R.M. (1991). Motivation and Education: The Self-Determination Perspective. Educational Psychologist, 26(3 \& 4), 325-346.

[11] Diamantopoulos, A., Sarstedt, M., Fuchs, C., Wilczynski, P., \& Kaiser, S. (2012). Guidelines for choosing between multi-item and single-item scales for construct measurement: a predictive validity perspective. Journal of the Academy of Marketing Science, 40(3), 434-449. 10.1007/s11747-011-0300-3

[12] Duncan, T.G., \& McKeachie, W.J. (2005). The Making of the Motivated Strategies for Learning Questionnaire. Educational Psychologist, 40(2), 117-128.

[13] Frey, N., \& Fisher, D. (2010). Motivation Requires a Meaningful Task. English Journal, 100(1), 30-36.

[14] Fulton, E., \& Turner, L.A. (2008). Students' Academic Motivation: Relations with Parental Warmth, Autonomy Granting, and Supervision. Educational Psychology, 28(5), 521-534.

[15] Gbollie, C., \& Keamu, H.P. (2017). Student Academic Performance: The Role of Motivation, Strategies, and Perceived Factors Hindering Liberian Junior and Senior High School Students Learning. Education Research International, 2017, 0-11. https://dx.doi.org/ $10.1155 / 2017 / 1789084$

[16] Gonzalez, R., \& Padilla, A.M. (1997). The academic resilience of Mexican American high school Students. Hispanic Journal of Behavioural Sciences, 19(3), 301-317.

[17] Gosling, S. D., Rentfrow, P. J., \& Swann, W. B., Jr. (2003). A very brief measure of the Big Five personality domains. Journal of Research in Personality, 37, 504-528.

[18] Guay, F., Chanal, J., Ratelle, C.F., Marsh, H.W., Larose, S., \& Boivin, M. (2010). Intrinsic, identified, and controlled types of motivation for school subjects in young elementary school children. British Journal of Educational Psychology, 80(4), 711-735.

[19] Haimovitz, K., Corpus, J.H., \& Wormington S. (2011). Dangerous mindsets: How beliefs about intelligence predict motivational change. Learning and Individual Differences, 21(6), 747-752.

[20] Hanson, T.L., \& Austin, G. (2003). Student health risks, resilience and academic performance in California: Year 2 report, longitudinal analysis. Wested Press, Los Alamitos.

[21] Herrero, D.M. (2014). The relationship among achievement motivation, hope, and students enrolled in a hispanic-serving institution (doctoral dissertation). Texas A\&M University. 
[22] Hoang, T.M.N., \& Nguyen, T.K. (2016). Phan tich cac nhan to tac dong den dong luc hoc tap cua sinh vien Kinh te Truong Dai hoc Can Tho. Can Tho University Journal of Science, 46, 107-115.

[23] Hudson, W.E. (2007). The relationship between academic self-efficacy and resilience to grades of students admitted under special criteria (doctoral dissertation). The Florida State University.

[24] Jung, J., \& Kim, Y. (2012). Causes of newspaper firm employee burnout in Korea and its impact on organizational commitment and turnover intention. International Journal of Human Resource Management, 23(17), 1-16.

[25] Komarraju, M., \& Karau, S.J. (2008). Relationships between the Perceived Value of Instructional Techniques and Academic Motivation. Journal of Instructional Psychology, 35(1), 70-82.

[26] Krejcie, R.V., \& Morgan, D.W. (1970). Determining sample size for research activities. Educational and Psychological Measurement, $30,607-610$.

[27] Lamb-Sinclair, A. (2017, June 16). Why Grades Are Not Paramount to Achievement. The Atlantic. https://www.theatlantic.com/ education/archive/2017/06/why-grades-are -not-the-key-to-achievement/530124/

[28] Lee, I. (2010). The Effect of Learning Motivation, Total Quality Teaching and Peer-Assisted Learning on Study Achievement: Empirical Analysis from Vocational Universities or Colleges' students in Taiwan. The Journal of Human Resource and Adult Learning, 6(2), 5673.

[29] Lepper, M.R., Greene, D., \& Nisbett, R.E. (1973). Undermining children's intrinsic interest with extrinsic reward: A test of the "overjustification" hypothesis. Journal of Personality and Social Psychology, 28(1), 129-137.

[30] Maslow, A.H. (1943). A Theory of Human Motivation. Psychological Review, 50(4), 370-396.

[31] Mwangi, C.N., Okatcha, F.M., Kinai, T.K., \& Ireri, A.M. (2015). Relationship between Academic Resilience and Academic Achievement among Secondary School Students in Kiambu County, Kenya. International Journal of School and Cognitive Psychology, 2(3), 1-5. http://dx.doi.org/10.4172/ijscp.S2-003

[32] Oberfield, Z. (2014). Motivation, change, and stability: Findings from an urban police department. The American Review of Public Administration, 44(2), 210-232.

[33] Paulhus, D.L., \& Vazire, S. (2007). The self-report method. In R.W. Robins, R.C. Fraley, \& R.F. Krueger (Eds.), Handbook of research methods in personality psychology (pp. 224-239). New York: The Guilford Press.

[34] Pike, G. R. (2011). Using college students' self-reported learning outcomes in scholarly research. New Directions for Institutional Research, 2011(150), 41-58.

[35] Pintrich, P.R. (1989). The dynamic interplay of student motivation and cognition in the college classroom. In Maehr M.L., \& Ames C. (Ed.), Advances in motivation and achievement: Motivation-enhancing environments, JAI Press, Greenwich, Vol. 6, pp. 117-160.

[36] Pintrich, P.R. \& De Groot, E.V., (1990). Motivational and Self-Regulated Learning Components of Classroom Academic Performance. Journal of Educational Psychology, 82(1), 33-40.

[37] Reis, S., Colbert, R., \& Hebert, T. (2005). Understanding resilience in diverse talented students in an urban high school. Roeper Review, $27(2), 110-120$.

[38] Robins, R. W., Hendin, H. M., \& Trzesniewski, K. H. (2001). Measuring global self-esteem: Construct validation of a single-item measure and the Rosenberg Self-EsteemScale. Personality and Social Psychology Bulletin, 27, 151-161.

[39] Rugutt, J., \& Chemosit, C.C. (2009). What Motivates Students to Learn? Contribution of Student-to-Student Relations, Student-Faculty Interaction and Critical Thinking Skills. Educational Research Quarterly, 32(3), 16-28.

[40] Directory of Statistical Analyses (2018). Pearson's Correlation Coefficient.Statistics Solutions.https://www.statisticssolutions.com/pearsons-correlation-coefficient/

[41] Stedul, M. (2013). How Motivation Affects Learning. The Inspired Classroom. https://theinspiredclassroom.com /2013/07/howmotivation-affects-learning/

[42] Steinmayr, R., Meißner, A., Weidinger, A.F., \& Wirthwein, L. (2014). Academic Achievement. Education Oxford Bibliographies. http://dx.doi.org/10.1093/ OBO/9780199756810-0108

[43] Turner, J.C., \& Patrick, H. (2008). How Does Motivation Develop and Why Does It Change? Reframing Motivation Research. Educational Psychologist, 43, 119 - 131.

[44] Usher, A., \& Kober, N.L. (2012). Student Motivation: An Overlooked Piece of School Reform. Summary. Center on Education Policy.

[45] Velez, J.J., \& Cano J., (2008). The relationship between teacher immediacy and student motivation. Journal of Agricultural Education, 49(3), 76-86. 
DOI: $10.51386 / 25815946 / \mathrm{ijsms}-\mathrm{v} 4 \mathrm{i} 6 \mathrm{p} 115$

Volume: 4 Issue: 6

November to December 2021

https://www.ijsmsjournal.org

[46] Waldersee, V. (2018, July 5). How your motivations change as you get older. YouGov. https://yougov.co.uk/topics /lifestyle/articlesreports/2018/07/05/ how-your-motivations-change-you-get-older

[47] Waninge, F., Dörnyei, Z., \& de Bot, K. (2014). Motivational dynamics in language learning: Change, stability, and context. Modern Language Journal, 98(3), 704-723.

[48] Wanous, J. P., \& Reichers, A. E. (1996). Estimating the reliability of a single-item measure. Psychological Reports, 78, 631-634.

[49] Wanous, J. P., Reichers, A. E., \& Hudy, M. J. (1997). Overall job satisfaction: How good are single-item measures? Journal of Applied Psychology, 82, 247-252.

[50] Waugh, R.F. (2002). Creating a scale to measure motivation to achieve academically: Linking attitudes and behaviours using Rasch measurement. Br J Educ Psychol,72(1), 65-86. 10.1348/000709902158775

[51] Waxman, H.C, \& Huang, S.L. (1997). Classroom instruction and learning environment differences between effective and ineffective urban elementary schools for African American Students. Urban Education, 32(1), 7-44.

[52] Williams, K.C., \& Williams, C.C. (2011). Five key ingredients for improving student motivation. Research in Higher Education Journal, 12, 104-122.

[53] Woods, S. A., \& Hampson, S. E. (2005). Measuring the Big Five with single items using a bipolar response scale. European Journal of Personality, 19, 373-390.

[54] Youngblut, J. M., \& Casper, G. R. (1993). Single-item indicators in nursing research. Research in Nursing and Health, 16, 459-465. 